\title{
ENDOCRINOLOGY IN PREGNANCY \\ Pheochromocytoma in pregnancy: case series and review of literature
}

\author{
K van der Weerd ${ }^{1, *}$, C van Noord ${ }^{1,2, *}$, M Loeve ${ }^{3}$, M F C M Knapen ${ }^{4,5}$, W Visser ${ }^{1,4}$, \\ W W de Herder ${ }^{1}$, G Franssen ${ }^{6}$, C D van der Marel $^{3}$ and R A Feelders ${ }^{1}$ \\ ${ }^{1}$ Department of Internal Medicine, Erasmus MC, University Medical Center, Rotterdam, The Netherlands, \\ ${ }^{2}$ Department of Internal Medicine, Maasstad Hospital, Rotterdam, The Netherlands, ${ }^{3}$ Department of \\ Anesthesiology, Unit of Obstetric Anesthesiology, ${ }^{4}$ Division of Obstetrics and Prenatal Medicine, Department of \\ Obstetrics and Gynaecology, Erasmus MC, University Medical Center, Rotterdam, The Netherlands, ${ }^{5}$ Foundation \\ Prenatal Screening Southwest Region of the Netherlands, Rotterdam, The Netherlands, and ${ }^{6}$ Department of \\ Surgery, Erasmus MC, University Medical Center, Rotterdam, The Netherlands \\ *( $\mathrm{K}$ van der Weerd and $\mathrm{C}$ van Noord contributed equally to this work)
}

\author{
Correspondence \\ should be addressed \\ to R A Feelders \\ Email \\ r.feelders@erasmusmc.nl
}

\begin{abstract}
Pheochromocytoma in pregnancy is extremely rare. Early recognition is crucial as antepartum diagnosis can largely decrease maternal and fetal mortality rates. As symptoms of pheochromocytoma are rather similar to those of other far more common causes of hypertension during pregnancy, timely diagnosis is a challenge. In pregnant patients, similar to non-pregnant patients, increased plasma and/or 24-h urine (nor)metanephrine concentrations most reliably confirm the diagnosis of pheochromocytoma. MRI and ultrasound are the only imaging modalities that can be used safely during pregnancy to localize the tumor. During pregnancy, pretreatment consists of alpha blockade as usual. However, dosing of $\alpha$-adrenergic receptor blockers during pregnancy is a challenge as hypertension must be treated while preserving adequate uteroplacental circulation. When the diagnosis is made within the first 24 weeks of pregnancy, it is generally recommended to remove the tumor in the second trimester, while resection is generally postponed till after delivery when the diagnosis is made in the third trimester and medical pretreatment is sufficient. Both during and after pregnancy, laparoscopic surgery is the preferred approach for resection of the tumor. There is no consensus in literature about the preferred route and timing of delivery. Therefore, in our opinion, decisions should be made on an individual basis by an experienced and dedicated multidisciplinary team. Over the last decades, maternal and fetal prognosis has improved considerably. Further increasing awareness of this rare diagnosis and treatment of these patients by a dedicated team in a tertiary referral hospital are critical factors for optimal maternal
\end{abstract} and fetal outcome.

\section{Introduction}

Pheochromocytomas in pregnancy are rare with an incidence of $0.007 \%$ in a large series describing 30246 pregnancies collected in 20 years (1). Autopsy studies, however, suggest a higher incidence (2). A timely diagnosis during pregnancy is important as maternal and fetal mortality is approximately $40-50 \%$ if untreated (3),
European Journal of Endocrinology

(2017) 177, R49-R58
() 2017 European Society of Endocrinology Printed in Great Britain decreasing to less than 5\% for maternal mortality and less than $15 \%$ for fetal mortality after treatment (4).

In this review, we will present 6 cases of pheochromocytoma or paraganglioma in pregnancy (Table 1). Four of them were diagnosed during pregnancy and two were suspected to have a pheochromocytoma 
Table 1 Patient characteristics.

\begin{tabular}{|c|c|c|c|c|c|c|}
\hline \multirow[b]{2}{*}{ Case } & \multirow[b]{2}{*}{ Diagnosis } & \multirow[b]{2}{*}{ Treatment } & \multirow[b]{2}{*}{ Delivery } & \multicolumn{2}{|c|}{ Outcome } & \multirow[b]{2}{*}{ Genetic backgrounc } \\
\hline & & & & Maternal & Fetal & \\
\hline 1 & PCC & Doxazosin & ELTCS & Uneventful & Healthy & NP \\
\hline 2 & PCC & $\begin{array}{l}\text { Doxazosin } \\
\text { Metoprolol }\end{array}$ & IVD & Uneventful & Healthy & NP \\
\hline 3 & PCC & $\begin{array}{l}\text { Doxazosin } \\
\text { Propranolol }\end{array}$ & NVD & Uneventful & Healthy & NP \\
\hline 4 & PCC & - & - & Died & Died & NT \\
\hline 5 & PGL & $\begin{array}{l}\text { Phenoxybenzamine } \\
\text { Metoprolol }\end{array}$ & ELTCS & Uneventful & Healthy & NT \\
\hline 6 & PGL & $\begin{array}{l}\text { Doxazosin } \\
\text { Propranolol }\end{array}$ & ELTCS & PGL in situ & Healthy & NT \\
\hline
\end{tabular}

PCC, pheochromocytoma; PGL, paraganglioma; ELTCS, elective lower segment transverse cesarean section; NVD, normal vaginal delivery (spontaneous and assisted together); IVD, induced vaginal delivery; NP, not present; NT, not tested.

during pregnancy in retrospect. We will discuss the medical (pre)treatment, timing of adrenalectomy, timing and route of delivery and perioperative management (overview of cases described in cited literature in Supplementary Tables 1 and 2, see section on supplementary data given at the end of this article).

\section{Case series}

\section{Two patients diagnosed with a pheochromocytoma during pregnancy}

In 2015, a 36-year-old woman was analyzed for short episodes of hypertension $(249 / 139 \mathrm{mmHg})$ accompanied by palpitations, dizziness and paling in her first pregnancy (Table 1, case 1). 24-h ambulatory blood pressure monitoring (24-h ABPM) showed short periods of hypertension (up to 190/110 $\mathrm{mmHg}$ ), and methyldopa was started. At presentation in our hospital, she was 11 weeks pregnant. Plasma normetanephrine levels were increased (Table 2, case 1). MRI showed a heterogeneous mass of the right adrenal gland $(6.6 \times 6.0 \times 6.7 \mathrm{~cm})$ with a high signal intensity on T2-weighted images (Fig. 1).
Treatment with doxazosin was started, and blood pressure values were normalized. At $15+6$ weeks of menstrual age, a laparoscopic adrenalectomy of the right adrenal gland was performed. During surgery, blood pressure was stabilized with noradrenaline, phentolamine, urapidil and esmolol keeping systolic blood pressure values between 110 and $200 \mathrm{mmHg}$. Histologically, the tumor was confirmed to be a pheochromocytoma. During the last months of the pregnancy, patient remained normotensive and repetitive measurements of serum normetanephrines and metanephrines were normal. At 38 weeks of menstrual age, an elective caesarian section was performed because of obstetric arguments (breech position). A $2225 \boldsymbol{g}$ $(p<2.3)$ healthy boy was born. Apgar scores were 6 and 10 respectively 1 and $5 \mathrm{~min}$ after birth. The delivery was uneventful with stable hemodynamics. Genetic analyses showed no abnormalities.

In 2015, a 35-year-old woman, was analyzed in a hospital elsewhere for chronic hypertension (Table 1, case 2). Laboratory analyses demonstrated an increase in plasma and urinary normetanephrines and metanephrines. MRI showed a mass of the right adrenal gland $(4.4 \times 2.8 \times 5.5 \mathrm{~cm})$, with heterogeneous

Table 2 Serum and urinary catecholamine metabolites.

\begin{tabular}{|c|c|c|c|c|c|c|c|}
\hline & \multirow[b]{2}{*}{ Normal value } & \multicolumn{6}{|c|}{ Cases } \\
\hline & & 1 & 2 & 3 & 4 & 5 & 6 \\
\hline \multicolumn{8}{|l|}{ Plasma } \\
\hline NMN, nmol/L & $0.05-0.6$ & 14.5 & 5.18 & - & - & - & - \\
\hline MN, nmol/L & $0.06-0.3$ & 0.12 & 0.81 & - & - & - & - \\
\hline 3-MT, nmol/L & $0.0-0.18$ & $<0.06$ & $<0.06$ & - & - & - & - \\
\hline \multicolumn{8}{|l|}{ Urine } \\
\hline NMN, $\mu \mathrm{mol} / \mathrm{mol}$ & $60-260$ & - & $812 *$ & $2654^{\dagger}$ & - & 4845 & 1818 \\
\hline $\mathrm{MN}, \mu \mathrm{mol} / \mathrm{mol}$ & $35-150$ & - & 262 & 125 & - & 91 & 55 \\
\hline
\end{tabular}

NMN, normetanephrines; MN, metanephrines; 3-MT, 3- methoxytyramine.

*normal value: $75-325 \mu \mathrm{mol} / \mathrm{mol}$; ${ }^{\dagger}$ normal value: $40-171 \mu \mathrm{mol} / \mathrm{mol}$. 


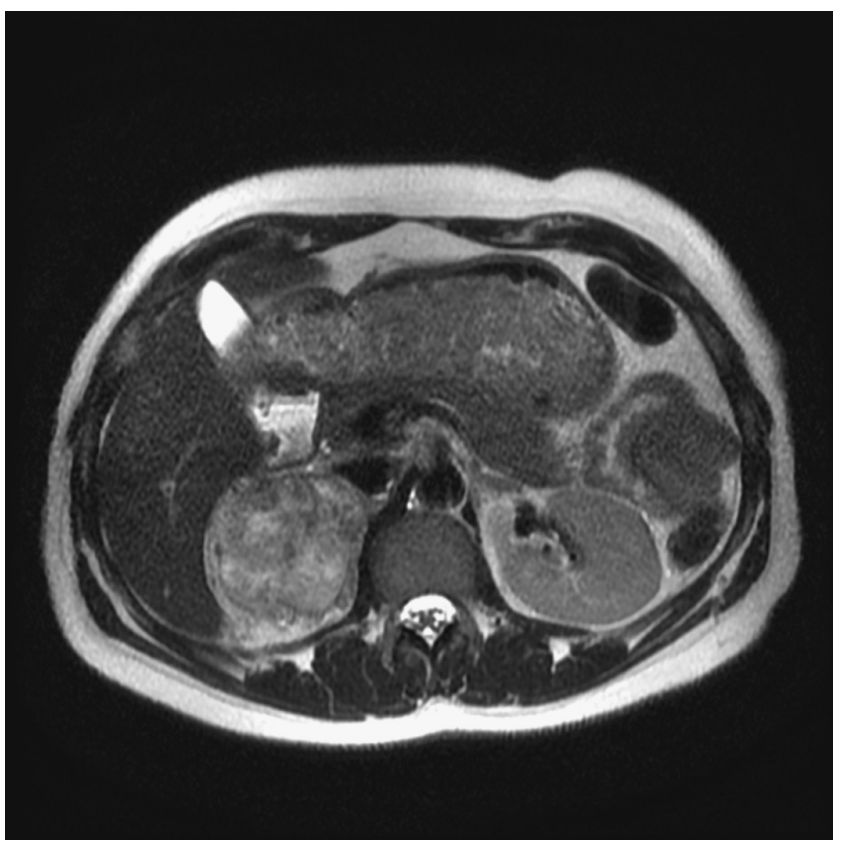

\section{Figure 1}

Magnetic resonance imaging of the abdomen.

This T2-weighted image shows a heterogeneous mass partially with high signal intensity of the right adrenal gland $(6.6 \times 6.0 \times 6.7 \mathrm{~cm})$.

signal intensity in T2-weighted images suggestive of a pheochromocytoma. At the time of diagnosis, the patient was pregnant, and it was her third pregnancy. The obstetric history was uneventful with two uncomplicated vaginal deliveries. During pregnancy, hypertension persisted (24-h ABPM: 150/108 $\mathrm{mmHg}$ ). At 23 weeks of menstrual age, the patient was referred to our hospital. Repeated biochemical evaluation showed an increase in plasma and urine normetanephrine and metanephrine levels (Table 2, case 2). As the patient was approaching the third trimester of her pregnancy and she responded well to medical treatment, it was decided to postpone adrenalectomy until after delivery. Treatment comprised of doxazosin and metoprolol. At 38 weeks of menstrual age, labor was induced with a balloon catheter and

Table 3 Cord blood catecholamines or metabolites.

\begin{tabular}{|c|c|c|c|c|c|}
\hline & \multirow[b]{2}{*}{ Normal value } & \multicolumn{2}{|c|}{ Case 2} & \multicolumn{2}{|c|}{ Case 5} \\
\hline & & Mother & Child & Mother & Child \\
\hline NMN, nmol/L & $0.05-0.6$ & 6.8 & 3.77 & & \\
\hline MN, nmol/L & $0.06-0.3$ & 1.23 & 0.48 & & \\
\hline 3-MT, nmol/L & $0.0-0.18$ & $<0.06$ & 0.27 & & \\
\hline $\mathrm{NA}, \mathrm{pg} / \mathrm{mL}$ & $<600$ & & & 4000 & 158 \\
\hline
\end{tabular}

augmented with oxytocin. Except for a short fluctuation in blood pressure after insertion of an epidural catheter (55/33-220/130 mmHg), delivery was uneventful. A $4210 \boldsymbol{g}$ (p 95-97.7) healthy boy was born vaginally. Apgar scores were 9 and 10 respectively 1 and 5 min after birth. Cord blood normetanephrine and metanephrine levels were increased but low compared to maternal levels (Table 3, case 2). The baby was admitted to the neonatal intensive care unit because of the maternal use of doxazosin but no hemodynamic complications occurred. Three days after delivery, a laparoscopic adrenalectomy was performed. Despite the use of magnesium sulfate, nitroprusside and noradrenaline, systolic blood pressure fluctuated between 70 and $200 \mathrm{mmHg}$ during surgery. Histologically, the tumor was confirmed to be a pheochromocytoma. During follow-up, the patient remained normotensive without medication. Serum normetanephrine and metanephrine levels remained normal. An additional MIBG scan after delivery did not show any abnormalities. Genetic analyses showed no abnormalities.

\section{Two patients suspected to have a pheochromocytoma during pregnancy in retrospect}

In 2008, a 31-year-old woman developed hypertension at 35 weeks of menstrual age of her first pregnancy (Table 1, case 3). Several days later, she developed headache and palpitations. As hypertension was considered to be due to preeclampsia, labor was induced. She had an uneventful vaginal delivery at 37 weeks of menstrual age under epidural analgesia. Unexpectedly, hypertension persisted after delivery, and further analysis was performed. Urine normetanephrine excretion was found to be increased (Table 2, case 3). An MRI showed a mass of the right adrenal gland $(4 \mathrm{~cm})$ with high signal intensity in T2-weighted images and an MIBG scan demonstrated increased MIBG-uptake in the right adrenal gland. Doxazosin and propranolol were started. Nineteen days after delivery, an uncomplicated laparoscopic adrenalectomy was performed. Histologically, the tumor was confirmed to be a pheochromocytoma. During follow-up, urinary normetanephrine excretion remained normal. Genetic analyses showed no abnormalities.

In 2012, a 35-year-old pregnant woman experienced an episode of acute shortness of breath at 28 weeks of menstrual age (Table 1, case 4). The obstetric history showed three uneventful pregnancies. When the ambulance arrived, the patient was found to be hypertensive $(150 / 120 \mathrm{mmHg})$. During transfer, she lost consciousness (Glasgow Coma Scale score of 3) and 
developed a bradycardia, directly followed by ventricular fibrillation. Cardiopulmonary resuscitation (CPR) was started. After arrival at the hospital, abdominal ultrasound showed an intrauterine fetal death and a cardiac ultrasound showed cardiomyopathy. Thirty minutes after arrival at the emergency department, CPR was stopped. It was not possible to trace whether a perimortem cesarean section during PCR was considered. Autopsy showed a pheochromocytoma of $6 \mathrm{~cm}$ of the right adrenal gland.

\section{Two patients diagnosed with a paraganglioma during pregnancy}

In 1999, an 18-year-old woman was referred to our hospital with episodes of hypotension and hypertension (24-h ABPM ranging from $87 / 45$ to $180 / 125 \mathrm{mmHg}$ ), flushes and palpitations at 27 weeks of menstrual age of her first pregnancy (Table 1, case 5). Urinary normetanephrine excretion was increased (Table 2, case 5). An MRI showed a mass of the right adrenal gland $(5.5 \times 5 \times 5 \mathrm{~cm})$ with high signal intensity in T2-weighted images. Phenoxybenzamine and metoprolol were started. An elective cesarean section was performed at 33 weeks of menstrual age, directly followed by resection of the paraganglioma. A $2085 \mathrm{~g}$ ( $\mathrm{p} 50-\mathrm{p}$ 80) healthy boy was born. Apgar scores were 2 and 6 respectively 1 and $5 \mathrm{~min}$ after birth. Compared to the maternal levels, cord blood noradrenaline levels were low (Table 3, case 5). Tumor resection was initiated laparoscopically but converted to an open resection because of the localization of the tumor between the renal vasculature and the vena cava inferior. At the start of the laparoscopy, blood pressure shortly increased to $300 / 150 \mathrm{mmHg}$, and during the remainder of the procedure, the patient remained normotensive. Histologically, the tumor was confirmed to be a paraganglioma. During follow-up, urinary normetanephrine excretion was normal. Thereafter, patient was lost to follow-up.

In 2008, a 37-year-old woman experienced paralysis of the left-sided hypoglossal nerve and the right-sided recurrent laryngeal nerve at 17 weeks of menstrual age in her second pregnancy (Table 1, case6). Obstetric history showed an ectopic pregnancy one year prior to this event. An MRI showed bilateral glomus caroticum tumors and a right-sided glomus vagale tumor. 24-h ABPM demonstrated a maximum blood pressure of $160 / 110 \mathrm{~mm} \mathrm{Hg}$. Urinary normetanephrine excretion was increased (Table 2, case 6). Doxazosin and propranolol were started. At 37 weeks of menstrual age, an elective cesarean section was performed under general anesthesia.
A $2890 \boldsymbol{g}$ (p 50) healthy boy was born. Apgar scores were 3 and 9 respectively 1 and $5 \mathrm{~min}$ after birth. Because surgery was not an option due to local invasion, the patient started with peptide receptor radiotherapy (PRRT) with

${ }^{177}$ lutetium-octreotate three months later (4 therapies and cumulative dose $29.9 \mathrm{GBq}$ ). MRI showed a decrease in size of the right-sided glomus tumors; however, the left-sided glomus caroticum remained unchanged. Over time, urinary normetanephrine levels decreased to $500 \mu \mathrm{mol} / \mathrm{mol}$ and doxazosin and propranolol could be stopped while remaining normotensive. Tumors have been stable in size until now.

\section{Review}

\section{Symptoms}

A pheochromocytoma in pregnancy is an extremely rare event. This may be one of the reasons that antepartum diagnosis is made in only $75 \%$ of cases (5). It is, however, crucial to make the diagnosis antepartum as timely treatment largely reduces maternal and fetal mortality rates $(5,6)$.

Symptoms of pheochromocytoma in pregnant patients do not differ from symptoms of pheochromocytoma in non-pregnant patients. In a large retrospective review of 117 case reports, hypertension was the most common presenting feature of pheochromocytoma in pregnancy, reported in $87 \%$ of pheochromocytomas and $86 \%$ of paragangliomas (6). Apart from hypertensive periods, periods of hypotension are commonly seen in patient with pheochromocytoma. During pregnancy, pheochromocytoma-related hypotension is found in about $50 \%$ of the patients (7).

As hypertension is a common complication of pregnancy occurring in $5-10 \%$ (8), it can be difficult to differentiate between a pheochromocytoma and more common causes of hypertension during pregnancy such as a chronic pre-existing hypertension and pregnancyrelated hypertension (gestational hypertension and (pre) eclampsia) (9). Several features must prompt further diagnostic testing for pheochromocytoma. Pregnancyrelated hypertension usually develops only after 20 weeks of menstrual age while pheochromocytoma can present with hypertension at any time during pregnancy. Moreover, hypertension in pheochromocytoma is often paroxysmal and periods of hypotension can occur as well (7). Therefore, especially patients presenting with severe hypertension before 20 weeks of menstrual age and/or paroxysmal hypertension or hypotension need 
to be screened for pheochromocytoma. In addition, accompanying symptoms can help to distinguish different forms of hypertension. Hypertension accompanied by not only headaches, palpitations and sweating but also hyperglycemia or cardiomyopathy is suggestive of pheochromocytoma, whereas hypertension accompanied by proteinuria and edema is more suggestive for pregnancy-related hypertension (10, 11). Finally, specific phenotypical features such as café-au-lait spots, freckles and fibromas might suggest a syndrome-based pheochromocytoma $(8,12)$.

Symptoms may worsen with advancing pregnancy due to an increased pressure on the tumor by the increasing abdominal distension, fetal movements and uterine contractions $(9,11)$. Moreover, estrogens have been suggested to act as a growth factor for adrenal tumors $(9,11,13,14)$.

Concerning our cases, in cases 1 and 5 probably accompanying symptoms led to a relatively early diagnosis. In case 3, diagnosis may have been delayed due to the late development of hypertension in the 35 th week of pregnancy.

\section{Diagnosis}

If a pheochromocytoma is suspected, diagnosis must be confirmed by demonstration of increased catecholamine levels or its metabolites. The most sensitive tests currently available include plasma and urinary (nor)metanephrines (15). Catecholamine metabolism is generally unaltered during healthy pregnancy, and even in patients with preeclampsia, plasma catecholamine levels are only slightly increased (9). Therefore, in pregnant patients, similar to non-pregnant patients, the most reliable test to confirm or exclude pheochromocytoma is analysis of plasma and/ or 24-h urine (nor)metanephrine concentrations (11, 16). Slightly increased results may be false positive due to limitations of the test or problems with collection of the materials. Results must also be interpreted with caution when patients are already using methyldopa or labetalol as these medications can lead to false-positive results in assays using liquid chromatography with fluorescence detection $(7,11)$. Provocation tests, such as the clonidine suppression test, should be avoided because of low sensitivity and potential serious side effects (9, 11). When plasma or urinary (nor)metanephrines are increased, additional imaging studies are needed to confirm diagnosis.

In pregnant women, ultrasound and MRI are the imaging modalities of choice to localize the tumor.
Usually MRI without gadolinium is accurate enough to diagnose pheochromocytoma, although gadolinium is not considered contraindicated during pregnancy (16). MIBG is not considered to be safe for the fetus because of placental transfer of the isotope resulting in radiation and iodine exposure $(17,18)$.

After the diagnosis, pheochromocytoma has been confirmed, genetic counseling should be considered during follow-up, as disease-causing mutations can be found in up to $20-30 \%$ of all patients $(16,19,20)$. Also in a series of patients diagnosed with pheochromocytoma during pregnancy, a disease-causing mutation was found in around $30 \%$ of patients (5). Based on the relatively young age of the patients with pheochromocytoma during pregnancy, the changes of finding a genetic defect might be even higher. In general, it has been suggested that genetic counseling should be considered in every patient with a pheochromocytoma based on individual suspicion, importance of diagnosis, negative impacts within the family and costs (16). Screening for genetic defects in patients who were diagnosed during pregnancy is not different from screening in other patients (16). The susceptibility genes that have been identified for pheochromocytoma include NF1, RET, VHL, succinate dehydrogenase subunits (SDHA, SDHB, SDHC and SDHD), co-factor for succinate dehydrogenase complex (SDHAF2), TMEM127, MAX, EGLN1/PHD2, EGLN2/PHD1, KIF1ß, IDH1, HIF2 $\alpha, F H$ and ATRX (7).

\section{Pretreatment}

Management of a patient with a pheochromocytoma is based on pretreatment with $\alpha$-adrenergic receptor blockade to counteract the effects of circulating catecholamines, followed by surgical removal of the tumor (16). Specific recommendations for the treatment of pheochromocytoma during pregnancy are mainly based on case reports, case series and expert opinion due to the rarity of the condition.

Pretreatment with $\alpha$-adrenergic receptor blockade for at least 10-14 days before surgery results in a lower risk of perioperative and postoperative complications due to a reduction in blood pressure, a reduced risk of paroxysmal increases in blood pressure and (partial) restoration of normal blood volume $(7,16)$. In non-pregnant patients, target blood pressure is $<130 / 80 \mathrm{mmHg}$ while in seated position and systolic blood pressure $>90 \mathrm{mmHg}$ while in standing position (16). In pregnant patients, target blood pressure is not known. In general, target blood pressure during pregnancy for chronic hypertension 
without signs of end-organ damage is $<150 / 100 \mathrm{mmHg}$ with diastolic blood pressure $>80 \mathrm{mmHg}$. In the presence of signs of end-organ damage, the target is lowered to $<140 / 90 \mathrm{mmHg}(8,21)$. The most important factor to take into account during pregnancy is preserving an adequate uteroplacental circulation. However, both an excess of catecholamines as well as relative hypotension can reduce uteroplacental circulation as uteroplacental circulation has no autoregulation and is therefore directly affected by changes in maternal blood pressure. High concentrations of catecholamines induce profound vasoconstriction of the maternal uterine arterial circulation, resulting in a compromised uteroplacental circulation, which may lead to intrauterine growth restriction, placental abruption or intrauterine hypoxia (9). Treatment with $\alpha$-adrenergic receptor blockers can counteract these effects but can result in hypotension compromising uteroplacental circulation as well (6). Dosing of $\alpha$-adrenergic receptor blockers during pregnancy is therefore a delicate balance between treating hypertension and uteroplacental vasoconstriction while maintaining adequate uteroplacental circulation (6, 7). Importantly, pregnant patients with normal blood pressure should be treated with low-dose $\alpha$-adrenergic blockers as well to prevent paroxysmal peaks in blood pressure (6).

Most commonly used $\alpha$-adrenergic receptor blockers are phenoxybenzamine (generally used dosages: $10-40 \mathrm{mg}$ twice a day) and doxazosin (generally used dosages: $4-16 \mathrm{mg}$ twice a day) (16). For many years, phenoxybenzamine (fetal risk category C) has been the alpha blocker of choice in pregnant patients with pheochromocytoma showing good neonatal outcomes in many case reports (7). A disadvantage of phenoxybenzamine might be that it is supposed to pass the placenta (22). As catecholamines do not largely pass the placenta due to the uptake of catecholamines by noradrenaline receptors on placental cells and breakdown of catecholamines by catechol-Omethyltransferase and monoamine oxidase in placental cells, there is no need to treat the fetus with transplacental administration of medication $(9,23)$. Moreover, maternal antihypertensive medication might cause unwanted side effects on the unborn child. Phenoxybenzamine has been associated with neonatal hypotension and respiratory depression. This is due to a counteracting effect on the catecholamine surge naturally occurring perinatally in the fetus to support adaptation to extrauterine life (22). Therefore, it is currently advised to monitor the neonate closely during the first days of life when the mother has been treated with phenoxybenzamine $(9,22)$.
More recently, doxazosin (fetal risk category C) has been used more often during pregnancy, with good neonatal outcomes so far. Advantages of doxazosin over phenoxybenzamine include the lower incidence of reflex tachycardia and less postoperative hypotension $(7,9)$. Although doxazosin may cross the human placental barrier, neonatal hypotension and respiratory depression have not been described $(6,24)$.

$\beta$-Adrenergic receptor blockers can be added to the treatment to counteract catecholamine-induced tachyarrhythmias and $\alpha$-adrenergic receptor blockadeinduced reflex tachycardia (7). As $\beta$-adrenergic receptor blockers have been associated with intrauterine growth restriction, it is generally advised to use them only for a short period of time during pregnancy (fetal risk category C) (25). When hypertension is not successfully stabilized with $\alpha$-adrenergic receptor blockers and no tachycardia is present, calcium channel blockers can be added to the treatment regime, which are generally thought to be safe during pregnancy (fetal risk category C) (16). Labetalol, a combined alpha- and beta-blocker, has been suggested as a single therapeutic agent in patients with pheochromocytoma. However, the relatively weak alpha blockade resulted in paroxysmal hypertension in several cases and is therefore no longer recommended (9). Also methyldopa, the most frequently used drug to treat hypertension during pregnancy is currently not recommended in pregnant patients with hypertension due to pheochromocytoma as it has been suggested to worsen hypertension (7).

Another important factor during pretreatment is restoring the intravascular volume. Usually a few days before surgery, intravenous fluids are started and patients receive a salt-increased diet. Restoring intravascular volume reduces the risk of large fluctuations in blood pressure during surgery and the risk of prolonged postoperative hypotension. Moreover, an adequate intravascular volume supports uteroplacental circulation $(7,9,16)$.

Finally, several commonly prescribed drugs should be avoided in patients with pheochromocytoma because they can induce a pheochromocytoma crisis by producing a sudden strong tumoral release of catecholamines or histamine. These drugs include for example corticosteroids (commonly prescribed to enhance fetal lung maturation in threatening preterm labor), opioids such as morphine and pethidine, anti-emetics such as metoclopramide and anesthetics such as thiopental, ketamine and ephedrine and muscle relaxants such as mivacurium $(11,26)$. 
Concerning our cases, cases 1, 2 and 6 were pretreated with doxazosin and case 5 with phenoxybenzamine, a $\beta$-blocker was added in cases 2,5 and 6 . The choice for doxazosin was based on the advantage of doxazosin with regard to neonatal complications as described previously and the long-term experience of the endocrinologists with doxazosin. In cases 2, 5 and 6, medical treatment was continued until delivery; in all these cases, no adverse events were seen in the neonates. Fortunately, case 3, in whom the diagnosis was made shortly after delivery, experienced an uncomplicated vaginal delivery despite the absence of medical pretreatment.

We were able to simultaneously collect maternal and umbilical cord catecholamines or metabolites in two cases (Table 3). Umbilical cord normetanephrine, metanephrine and 3-MT concentrations in case 2 and noradrenaline concentrations in case 5 were all increased, most probably demonstrating the expected fetal surge in catecholamines during labor. Normally, umbilical cord blood catecholamine concentrations even exceed venous maternal concentrations $(27,28)$, as is the case for 3-MT concentrations in umbilical cord blood in case 2. In our patients with a pheochromocytoma, however, in concordance with earlier case reports $(23,29)$, venous maternal concentrations of normetanephrines and metanephrines (case 2) and venous noradrenaline concentrations (case 5) clearly exceeded neonatal values due to tumoral overproduction (Tables 2 and 3 ). These data support the assumption that maternal catecholamines do not largely pass the placental barrier as described previously.

\section{Timing and method of adrenalectomy}

Surgery is the definite treatment for pheochromocytoma. Adequate timing of surgery remains a challenge and depends on gestational age, maternal and fetal response to medical pretreatment and location of the tumor ( 7 , 30 ). Nowadays, when the diagnosis is made within the first 24 weeks of pregnancy and adequate $\alpha$-blockade can be established within this time window, it is generally recommended to remove the tumor in the second trimester, after organogenesis is completed. In the third trimester, when medical pretreatment is sufficient, it is generally recommended to postpone resection till after delivery as the enlarged uterus diminishes accessibility of the tumor. Adrenalectomy can then be scheduled in the same session or at a later time several days to weeks after delivery $(7,9)$.
Laparoscopic surgery is the preferred approach to remove pheochromocytoma in the general population with reduced postoperative complications and similar or fewer hemodynamic fluctuations compared to the open approach $(31,32)$. This also applies for pregnant women with a pheochromocytoma as has been shown in a large case series in which laparoscopic surgery in the second trimester had a favorable outcome in 16 out of 18 patients (5).

During pregnancy, a transperitoneal approach should be used as an extraperitoneal approach requires prone positioning of the patient, which is contraindicated during pregnancy. For a transperitoneal approach, a lateral positioning is needed. A left lateral position for right adrenal extirpation is usually well tolerated as this position is also recommended to prevent pressure on the vena cava inferior. On the other hand, a right lateral position for left adrenal extirpation increases the risk for vena cava inferior compression thereby increasing the risk of uteroplacental hypoperfusion during surgery.

Concerning our cases, in case 1, the diagnosis was made in the first trimester allowing laparoscopic surgery during the second trimester, which was accomplished uneventfully. In cases 2 and 5, the diagnosis was made at the end of or after the second trimester and surgery was therefore performed after delivery.

As nowadays the preferred surgical approach is laparoscopy in an elective setting, we feel that, when no contraindications for laparoscopy are present, there is no argument for an elective cesarean delivery and open adrenalectomy in a combined surgical procedure. Therefore, in the second patient, a laparoscopic resection of the pheochromocytoma was planned several days after delivery, independent of the route of delivery.

\section{Timing and route of delivery}

When adrenalectomy has been performed successfully before 24 weeks of pregnancy, timing and route of delivery completely depends on obstetric arguments (9). However, for pregnant women with a pheochromocytoma in situ, there is to our knowledge no consensus in the literature regarding the preferred route of delivery. Previous case reports suggested a higher maternal mortality rate after vaginal delivery in contrast with elective cesarean section (3). Therefore, elective cesarean section was long considered the preferred route of delivery (9). However, in the current era of obstetric and anesthesiological management, these case series should be interpreted with caution as they were published several decades ago. 
Recent literature describes successful and safe vaginal delivery under adequate epidural analgesia to reduce pain and stress $(6,33,34,35)$. The period of active pushing and stress during the second stage of labor can be shortened (if necessary) or even be avoided by performing an instrumental vaginal delivery by ventouse of forcipal extraction. Moreover, especially multiparous women under epidural anesthesia, usually have a short second stage of labor and active pushing can be minimized. On the other hand, oxytocin and other uterotonic medication should be used with caution, as they may cause hemodynamic effects, such as tachycardia and hypotension (7).

Arguments supporting cesarean section include the presence of a controlled environment with close monitoring and readily availability of treatment options for hemodynamic instability. Moreover, epidural, spinal, general and combined anesthetic techniques have been described to be safe in pregnant women with a pheochromocytoma $(36,37)$. On the other hand, a cesarean section is potentially more stressful than a vaginal delivery as it can lead to excessive blood loss due to the uterine incision and a catecholamine excess by manipulation of the peritoneum or, in fact, the tumor.

Concerning our cases, in cases 5 and 6 , a cesarean section was chosen mainly based on the experience in the literature in that era (1999 and 2008). In the most recent case (case 2, 2015), however, vaginal delivery was chosen, which was successful. Oxytocin in this case did not cause any hemodynamic instability. Based on our experiences and recent literature, we feel that decisions about timing and route of delivery should be made on an individual basis by an experienced and dedicated multidisciplinary team. Considerations that should be taken into account include the obstetric history (mainly parity and route of previous deliveries), maternal and fetal conditions, clinical response to pretreatment and the personal preference of the patient. Moreover, planned induction of labor just before the term date should be considered to guarantee the direct availability of an experienced team to support the delivery and possible complications.

\section{Perioperative management}

Adrenalectomy should be planned after proper medical pretreatment (for at least 10 to 14 days) as described previously. General peri-operative considerations in any patient with a pheochromocytoma, pregnant or not, include close monitoring during procedures that can induce acute catecholamine excess, such as moving the patient on the operating table, induction of anesthesia, tracheal intubation and tumor manipulation. Known risk factors for intraoperative hypertensive events include a higher preoperative plasma norepinephrine concentration, a larger maximal diameter of the tumor and a higher blood pressure before and after alphaadrenergic receptor blockade (38).

In case of acute hypertension, a rapidly acting alpha antagonist, calcium channel blockers or magnesium sulfate can be given safely during pregnancy. In case of tachycardia, rapid and short-acting beta-blockers can be used. The use of nitroprusside during pregnancy is debated as it theoretically may cause fetal cyanide toxicity (7).

Several pregnancy-related physiological changes should be taken into account when adrenalectomy is performed in the second trimester. Due to swelling of oropharyngeal tissues and a decreased caliber of the glottis opening airway management can become more difficult (39). Moreover, aortacaval compression by the pregnant uterus may occur after approximately 20-24 weeks of menstrual age. Therefore, left uterine displacement by $15-20^{\circ}$ is recommended from 20 weeks of menstrual age onward (39). In addition, due to the uterus' lack of autoregulation, the uteroplacental circulation may be compromised during periods of hemodynamic instability leading to fetal distress.

Special consideration should be given to cases in which maternal hypertension is not (yet) optimally controlled, such as when labor is unexpected, premature or in cases of undiagnosed pheochromocytoma. In these conditions, hypertensive emergency, acute pulmonary edema, malignant arrhythmias, myocardial ischemia or infarction, aortic dissection, cardiac failure and hemodynamic collapse are well-recognized complications of pheochromocytoma, and the risk of death is high after such acute presentations unless appropriate therapy is instituted quickly (34). Few case reports have described such conditions, with varying outcomes for both mother and child (1, 17, 34, 35, 40, 41, 42, 43).

Concerning our cases, in cases 5 and 6, cesarean section and adrenalectomy were performed in a combined procedure. The complete procedures including the cesarean section were performed under general anesthesia. This resulted in fetal exposure to anesthetics and opioids for $60-90 \mathrm{~min}$ preceding delivery due to placental transfer. This may explain the babies' initial low APGAR scores despite adequate umbilical cord $\mathrm{pH}$ and base excess (BE) in cases 5 and $6(\mathrm{pH} 7.29$ and $\mathrm{BE}-0.5$ in case 5 and $\mathrm{pH} 7.28$ and $\mathrm{BE}$ 
-1.0 in case 6$)$. In case 2 , it was decided to perform an induced vaginal delivery under epidural anesthesia as this patient already had two successful vaginal deliveries before and recent literature supports that vaginal delivery under epidural anesthesia is safe and successful under optimal circumstances. Adrenalectomy was performed 3 days after delivery. Importantly, prior to both induction of labor and adrenalectomy, the patient was optimally pretreated with alpha- and beta-blockade, and intravascular volume was restored. Delivery and adrenalectomy were uneventful.

\section{Conclusion}

Pheochromocytoma during pregnancy is a rare entity with a high maternal and fetal mortality rate. Diagnosing pheochromocytoma during pregnancy can be difficult due to the low incidence of pheochromocytoma during pregnancy $(0.007 \%)$ compared to the incidence of hypertension during pregnancy (5-10\%). Timely diagnosis and proper treatment are however of utmost importance to reduce maternal and fetal mortality.

Treatment of pheochromocytoma during pregnancy is rather specialized and should be performed in a specialized tertiary center. Important issues that need special attention include pretreatment, timing of surgery and route of delivery. During pretreatment, overdosing of $\alpha$-adrenergic receptor blockade should be avoided to preserve uteroplacental circulation. Surgery is preferably performed in the second trimester or postponed till delivery and thus depends largely on when the diagnosis was made. A laparoscopic route in the breech position is preferable. When surgery is postponed until delivery, it has long been advocated to perform a cesarean section. More recently, after cases of successful and safe vaginal deliveries under adequate epidural analgesia, this has been debated, and vaginal delivery should be considered as a serious option for delivery.

Due to these advances in pretreatment of patients with $\alpha$-blockade and technical progress in surgical and anesthesiological techniques, over the last past decades, maternal and fetal prognosis have already considerably improved $(3,5,6,7,9)$.

Overall, awareness of this rare diagnosis and treatment of these patients by a dedicated team, consisting of an obstetric, anesthesiological, internal medicine, intensive care and pediatric consultant in a tertiary referral hospital are critical factors for an optimal maternal and fetal outcome.
Supplementary data

This is linked to the online version of the paper at http://dx.doi.org/10.1530/ EJE-16-0920.

\section{Declaration of interest}

The authors declare that there is no conflict of interest that could be perceived as prejudicing the impartiality of the research reported.

\section{Funding}

This study did not receive any specific grant from any funding agency in the public, commercial or not-for-profit sector.

\section{References}

1 Harrington JL, Farley DR, van Heerden JA \& Ramin KD. Adrenal tumors and pregnancy. World Journal of Surgery 199923 182-186. (doi:10.1007/PL00013159)

2 Sutton MG, Sheps SG \& Lie JT. Prevalence of clinically unsuspected pheochromocytoma. Review of a 50-year autopsy series. Mayo Clinic Proceedings 198156 354-360.

3 Schenker JG \& Granat M. Phaeochromocytoma and pregnancy-an updated appraisal. Australian and New Zealand Journal of Obstetrics and Gynaecology 198222 1-10. (doi:10.1111/j.1479-828X.1982.tb01388.x)

4 Sarathi V, Lila AR, Bandgar TR, Menon PS \& Shah NS. Pheochromocytoma and pregnancy: a rare but dangerous combination. Endocrine Practice 201016 300-309. (doi:10.4158/ EP09191.RA)

5 Biggar MA \& Lennard TW. Systematic review of phaeochromocytoma in pregnancy. British Journal of Surgery 2013100 182-190. (doi:10.1002/bjs.8976)

6 Wing LA, Conaglen JV, Meyer-Rochow GY \& Elston MS. Paraganglioma in pregnancy: a case series and review of the literature. Journal of Clinical Endocrinology and Metabolism 2015100 3202-3209. (doi:10.1210/jc.2015-2122)

7 Prete A, Paragliola RM, Salvatori R \& Corsello SM. Management of catecholamine-secreting tumors in pregnancy: a review. Endocrine Practice 201522 357-370. (doi:10.4158/EP151009.RA)

8 Vest AR \& Cho LS. Hypertension in pregnancy. Current Atherosclerosis Reports 201416 395. (doi:10.1007/s11883-013-0395-8)

9 Lenders JW. Pheochromocytoma and pregnancy: a deceptive connection. European Journal of Endocrinology 2012166 143-150. (doi:10.1530/EJE-11-0528)

10 Malha L \& August P. Secondary hypertension in pregnancy. Current Hypertension Reports 201517 53. (doi:10.1007/s11906-015-0563-z)

11 Kamoun M, Mnif MF, Charfi N, Kacem FH, Naceur BB, Mnif F, Dammak M, Rekik N \& Abid M. Adrenal diseases during pregnancy: pathophysiology, diagnosis and management strategies. American Journal of the Medical Sciences 2014347 64-73. (doi:10.1097/ MAJ.0b013e31828aaeee)

12 Gainder S, Raveendran A, Bagga R, Saha SC, Dhaliwal LK \& Bhansali AK. Phaeochromocytoma in pregnancy can mimic severe hypertensive disorders. Journal of Obstetrics and Gynaecology 201131 539-541. (doi:10.3109/01443615.2011.587909)

13 Refaat MM, Idriss SZ \& Blaszkowsky LS. Case report: an unusual case of adrenal neuroblastoma in pregnancy. Oncologist 200813 152-156. (doi:10.1634/theoncologist.2006-0180)

14 Eschler DC, Kogekar N \& Pessah-Pollack R. Management of adrenal tumors in pregnancy. Endocrinology and Metabolism Clinics of North America 201544 381-397. (doi:10.1016/j.ecl.2015.02.006)

15 Boyle JG, Davidson DF, Perry CG \& Connell JM. Comparison of diagnostic accuracy of urinary free metanephrines, vanillyl mandelic 
Acid, and catecholamines and plasma catecholamines for diagnosis of pheochromocytoma. Journal of Clinical Endocrinology and Metabolism 200792 4602-4608. (doi:10.1210/jc.2005-2668)

16. Lenders JW, Duh QY, Eisenhofer G, Gimenez-Roqueplo AP, Grebe SK, Murad MH, Naruse M, Pacak K \& Young WF Jr. Pheochromocytoma and paraganglioma: an endocrine society clinical practice guideline. Journal of Clinical Endocrinology and Metabolism 201499 1915-1942. (doi:10.1210/jc.2014-1498)

17 Plu I, Sec I, Barres D \& Lecomte D. Pregnancy, cesarean, and pheochromocytoma: a case report and literature review. Journal of Forensic Sciences 201358 1075-1079. (doi:10.1111/1556-4029.12107)

18 Abdelmannan D \& Aron DC. Adrenal disorders in pregnancy. Endocrinology and Metabolism Clinics of North America 201140 779-794. (doi:10.1016/j.ecl.2011.09.001)

19 Buffet A, Venisse A, Nau V, Roncellin I, Boccio V, Le Pottier N, Boussion M, Travers C, Simian C, Burnichon N et al. A decade (20012010) of genetic testing for pheochromocytoma and paraganglioma. Hormone and Metabolic Research 201244 359-366. (doi:10.105 5/s-0032-1304594)

20 Amar L, Bertherat J, Baudin E, Ajzenberg C, Bressac-de Paillerets B, Chabre O, Chamontin B, Delemer B, Giraud S, Murat A et al. Genetic testing in pheochromocytoma or functional paraganglioma. Journal of Clinical Oncology 200523 8812-8818. (doi:10.1200/JCO.2005.03.1484)

21 NICE Guideline 107: hypertension in pregnancy. www.nice.org.uk/ guidance/CG107 publication date august 2010.

22 Aplin SC, Yee KF \& Cole MJ. Neonatal effects of long-term maternal phenoxybenzamine therapy. Anesthesiology 2004100 1608-1610. (doi:10.1097/00000542-200406000-00039)

23 Dahia PL, Hayashida CY, Strunz C, Abelin N \& Toledo SP. Low cord blood levels of catecholamine from a newborn of a pheochromocytoma patient. European Journal of Endocrinology 1994 130 217-219. (doi:10.1530/eje.0.1300217)

24 Versmissen J, Koch BC, Roofthooft DW, Ten Bosch-Dijksman W, van den Meiracker AH, Hanff LM \& Visser W. Doxazosin treatment of phaeochromocytoma during pregnancy: placental transfer and disposition in breast milk. British Journal of Clinical Pharmacology 2016 82 568-569. (doi:10.1111/bcp.12981)

25 Butters L, Kennedy S \& Rubin PC. Atenolol in essential hypertension during pregnancy. BMJ 1990301 587-589. (doi:10.1136/ bmj.301.6752.587)

26 Rosas AL, Kasperlik-Zaluska AA, Papierska L, Bass BL, Pacak K \& Eisenhofer G. Pheochromocytoma crisis induced by glucocorticoids: a report of four cases and review of the literature. European Journal of Endocrinology 2008158 423-429. (doi:10.1530/EJE-07-0778)

27 Paulick R, Kastendieck E \& Wernze H. Catecholamines in arterial and venous umbilical blood: placental extraction, correlation with fetal hypoxia, and transcutaneous partial oxygen tension. Journal of Perinatal Medicine 198513 31-42. (doi:10.1515/jpme.1985.13.1.31)

28 Vogl SE, Worda C, Egarter C, Bieglmayer C, Szekeres T, Huber J \& Husslein P. Mode of delivery is associated with maternal and fetal endocrine stress response. BJOG $2006 \mathbf{1 1 3}$ 441-445. (doi:10.1111/ j.1471-0528.2006.00865.x)
29 Saarikoski S. Fate of noradrenaline in the human foetoplacental unit. Acta Physiologica Scandinavica Journal 1974421 1-82.

30 Oliva R, Angelos P, Kaplan E \& Bakris G. Pheochromocytoma in pregnancy: a case series and review. Hypertension 201055 600-606. (doi:10.1161/HYPERTENSIONAHA.109.147579)

31 Gumbs AA \& Gagner M. Laparoscopic adrenalectomy. Best Practice and Research Clinical Endocrinology and Metabolism 200620 483-499. (doi:10.1016/j.beem.2006.07.010)

32 Fernandez-Cruz L, Taura P, Saenz A, Benarroch G \& Sabater L. Laparoscopic approach to pheochromocytoma: hemodynamic changes and catecholamine secretion. World Journal of Surgery 1996 20 762-768; discussion 768. (doi:10.1007/s002689900116)

33 Kapoor G, Salhan S, Sarda N, Sarda AK \& Aggarwal D. Phaeochromocytoma in pregnancy: safe vaginal delivery, is it possible? Journal of the Indian Medical Association 2013111 266-267.

34 Desai AS, Chutkow WA, Edelman E, Economy KE \& Dec GW Jr. Clinical problem-solving. A crisis in late pregnancy. New England Journal of Medicine 2009361 2271-2277. (doi:10.1056/ NEJMcps0708258)

35 Strachan AN, Claydon P \& Caunt JA. Phaeochromocytoma diagnosed during labour. British Journal of Anaesthesia 200085 635-637. (doi:10.1093/bja/85.4.635)

36 Cammarano WB, Gray AT, Rosen MA \& Lim KH. Anesthesia for combined cesarean section and extra-adrenal pheochromocytoma resection: a case report and literature review. International Journal of Obstetric Anesthesia 19976 112-117. (doi:10.1016/S0959. 289X(97)80008-8)

37 Stonham J \& Wakefield C. Phaeochromocytoma in pregnancy. Caesarean section under epidural analgesia. Anaesthesia 198338 654-658. (doi:10.1097/00132582-198312000-00026)

38 Bruynzeel H, Feelders RA, Groenland TH, van den Meiracker AH, van Eijck CH, Lange JF, de Herder WW \& Kazemier G. Risk factors for hemodynamic instability during surgery for pheochromocytoma. Journal of Clinical Endocrinology and Metabolism 201095 678-685. (doi:10.1210/jc.2009-1051)

39 Cheek TG \& Baird E. Anesthesia for nonobstetric surgery: maternal and fetal considerations. Clinical Obstetrics and Gynecology 200952 535-545. (doi:10.1097/GRF.0b013e3181c11f60)

40 Ahlawat SK, Jain S, Kumari S, Varma S \& Sharma BK. Pheochromocytoma associated with pregnancy: case report and review of the literature. Obstetrical and Gynecological Survey $1999 \mathbf{5 4}$ 728-737. (doi:10.1097/00006254-199911000-00025)

41 Gill PS. Acute heart failure in the parturient - do not forget phaeochromocytoma. Anaesth Intensive Care 200028 322-324.

42 Hudsmith JG, Thomas CE \& Browne DA. Undiagnosed phaeochromocytoma mimicking severe preeclampsia in a pregnant woman at term. International Journal of Obstetric Anesthesia $2006 \mathbf{1 5}$ 240-245. (doi:10.1016/j.ijoa.2005.11.003)

43 Zangrillo A, Valentini G, Casati A \& Torri G. Myocardial infarction and death after caesarean section in a woman with protein $\mathrm{S}$ deficiency and undiagnosed phaeochromocytoma. European Journal of Anaesthesiology 1999 16 268-270. (doi:10.1097/00003643-199904000-00012)

Received 5 November 2016

Revised version received 29 March 2017

Accepted 5 April 2017 